\title{
Desigualdade de acesso ao Programa Ciência sem Fronteiras: uma interlocução com a perspectiva dos estudos de gênero
}

\author{
Catarina Barbosa Torres Gomes' (iD 0000-0001-6133-7908 \\ 'Centro Federal de Educação e Tecnologia de Minas Gerais, Araxá, MG, Brasil. \\ 38180-510 - diretoria.araxa@cefetmg.br
}

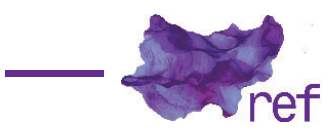

Resumo: Este artigo se propõe a apresentar e discutir parte de uma pesquisa mais ampla expondo o perfil sociológico do bolsista do Programa Ciência sem Fronteiras sob as perspectivas da divisão sexual nas áreas de conhecimento e na mobilidade acadêmica internacional. O enfoque engloba a análise da participação das mulheres nessa mobilidade, no âmbito do País, e estreita-se de modo mais detalhado sobre o campus empírico do estudo, que é a Universidade Federal de Minas Gerais (UFMG). A discussão central aborda o percentual de mulheres que participaram do Programa Ciência sem Fronteiras, indagando as possíveis razões que impactaram essa participação tanto sob a perspectiva da literatura que investiga a divisão sexual na pesquisa científica no Brasil quanto da proficiência linguística. Ademais, estabelece-se uma comparação entre o contingente feminino de bolsistas no Programa Ciência sem Fronteiras e outros programas de mobilidade acadêmica no mundo.

Palavras-chave: mulheres; ciência sem fronteira; divisão sexual na formação; internacionalização acadêmica.

\begin{abstract}
Inequality of Access to the Science Without Borders Program: A Dialogue with the Perspective of Gender Studies

Abstract: This article proposes to present and discuss part of a broader research, exposing the sociological profile of the Science Without Borders scholarship holder from the perspective of the sexual division in the areas of knowledge and international academic mobility. The focus includes the analysis of the participation of women in this mobility, within the country, and narrows in more detail on the empirical campus of the study, which is the Federal University of Minas Gerais (UFMG). The central discussion addresses the percentage of women who participated in the CSF, asking the possible reasons that impacted this participation both from the perspective of the literature that investigates the sexual division in scientific research in Brazil and linguistic proficiency. In addition, a comparison is made between the female contingent of fellows in the CSF and other academic mobility programs in the world.
\end{abstract}

Keywords: Women; Science without Borders; Sexual division in formation; Academic internationalization.

Desigualdad de acceso al programa Ciencia sin Fronteras: un diálogo con la perspectiva de los estudios de género

Resumen: Este artículo propone presentar y discutir parte de una investigación más amplia, exponiendo el perfil sociológico de la becaria Ciencia Sin Fronteras desde la perspectiva de la división sexual en las áreas de conocimiento y movilidad académica internacional. El enfoque incluye el análisis de la participación de las mujeres. en esta movilidad, dentro del país, y se acota con más detalle en el campus empírico del estudio, que es la Universidad Federal de Minas Gerais (UFMG). La discusión central aborda el porcentaje de mujeres que participaron en el CSF, preguntando las posibles razones que impactaron esta participación tanto desde la perspectiva de la literatura que investiga la división sexual en la investigación científica en Brasil como la competencia lingüística. Además, se hace una comparación entre el contingente femenino de becarias del CSF y otros programas de movilidad académica en el mundo.

Palabras clave: mujeres; ciencia sin límites; división sexual en la formación, internacionalización académica. 


\section{Introdução}

O acesso das estudantes brasileiras ${ }^{1}$ ao Programa Ciência sem Fronteiras ${ }^{2}$ evidenciouse como parte de um problema de pesquisa de doutorado, ${ }^{3}$ realizada na UFMG, na linha de pesquisa Sociologia da Educação. Considerando os avanços dos debates sobre o tema das desigualdades de gênero na ciência, bem como nos campos de formação, o principal pressuposto da tese era o de que o alcance a esse benefício, concedido mediante política pública de apoio à internacionalização da formação, seria socialmente desigual, visto que o atendimento às demandas do Programa requeria a proficiência em língua estrangeira, o bom desempenho acadêmico, além do pertencimento às áreas prioritárias. Esperava-se que as desigualdades do acesso à bolsa se manifestassem antes, como distinções típicas das diferenças de classes, principalmente pela posse do capital econômico, e na meritocracia, pela posse do capital cultural, escolar e linguístico. Porém, elas também se mostraram plausíveis em relação às desigualdades de gênero, para as quais se elaboraram algumas perguntas: Mais mulheres ou homens tiveram acesso ao CsF? Se houve diferenças percentuais de participação, por quê? Seriam questões ligadas ao mérito, isto é, ao desempenho acadêmico? Seriam problemas relacionados à proficiência linguística?

Mediante tais interrogações, o estudo da variável "sexo" tornou-se parte inevitável do objeto pesquisado. Para tanto, o pressuposto de pesquisa baseou-se em pesquisas nacionais, que abordam a perspectiva da divisão sexual no campo da ciência e tecnologia no Brasil, e que, segundo estudos de Luzinete Simões Minella (2013), "tem se constituído, ao longo do tempo, como um campo de disputas no qual se entrelaçam diferentes 'eixos de subordinação'" (p. 97). Também foram consideradas as contribuições de pesquisas que investigam a participação das mulheres na área de engenharia, majoritária entre os beneficiários do CsF, e os estudos que interrogam a participação das mulheres nas áreas científicas do CNPq. Como não poderia deixar de ser, as leituras foram inspiradas pelas contribuições de Maria Margareth Lopes (2006), a qual questiona as negligências históricas da ciência para com as mulheres, rememorando, dentre muitas, as perspectivas de Ludmilla Jordanova (1999), para quem o conceito de gênero não é mais necessariamente universal e atemporal. Algumas pesquisas internacionais, há algum tempo, vêm investigando o percentual de mulheres em mobilidade pelo mundo, e fornecem interessante parâmetro para as análises expostas.

O artigo está estruturado em quatro seções. Inicialmente, apresentam-se aspectos da mobilidade acadêmica na perspectiva histórica e de seus fluxos, seguidos de uma análise de sua institucionalização por meio de políticas contratuais entre os países e instituições conveniadas. A segunda seção constitui-se da metodologia da pesquisa, e a terceira, pela intersecção entre o referencial teórico e a discussão dos resultados, implicados pelos estudos que apresentam o cenário das discussões sobre a divisão sexual no campo das pesquisas e da formação universitária brasileira. Nessa seção, delineia-se, também, uma análise comparativa sobre as estatísticas da participação feminina em programas de mobilidade em alguns países e o Brasil. Na última seção, apresentam-se as conclusões do estudo.

\section{O Panorama da Mobilidade Estudantil: história e fluxos}

A mobilidade estudantil remonta à Europa Medieval, como apontam os estudos de Chistophe Charles e Jacques Verger (1996). Ainda no Brasil dos tempos imperiais, eram frequentes as viagens da elite brasileira à Europa, para fins de formação. Já no século XX, o fenômeno deu um grande salto histórico logo após a Segunda Guerra, quando surge um modelo mais sistematizado e solidário de mobilidade, baseado em acordos culturais e científicos firmados entre os países. Essa movimentação solidária gerou um amplo processo de internacionalização da educação superior que envolvia a ida de estudantes, sobretudo dos EUA, para a Europa (Hans DE WIT, 2008).

No Brasil, a partir dos anos 1950/60, a mobilidade acadêmica decorreu de uma política pública nacional, instituída para pós-graduar o corpo docente das universidades que iria buscar por essa formação fora do País, fomentado pela Capes e CNPq.

Os avanços da ciência e da tecnologia, cada vez mais crescentes nos países desenvolvidos, situam a mobilidade estudantil acadêmica em um novo patamar geopolítico, visto que refletem uma outra face das relações de dependência entre os países. Para ter acesso às novas plataformas de pesquisas científicas mundiais, os países elaboram programas de cooperação internacional.

Estatísticas internacionais calculadas pela OCDE (2010) identificaram que os fluxos migratórios de estudantes se fazem, sobretudo, dos países ditos do "Sul" (menos desenvolvidos) para os países ditos do "Norte" (desenvolvidos). Os percentuais globais de distribuição desses estudantes indicam que até $20 \%$ vão para os EUA, e $12 \%$ seguem para o Reino Unido. Em torno de $8 \%$ optam pela

' Estudantes vinculadas às modalidades do Programa CsF: graduação e pós-graduação.

2 Será designado como CsF a partir desse ponto.

${ }^{3}$ Informação suprimida para evitar identificação da autoria. Nessa nota, será creditado agradecimento à orientadora da pesquisa. 
França, enquanto a Alemanha recebe a mesma quantia. O destino de $14 \%$ é a Austrália e a China, que dividem esse percentual. O Canadá é o destino de 5\% (Susan ROBERTSON, 2011.

A mobilidade acadêmica tem sido objeto de pesquisa de estudiosos que a definem como um fenômeno que ocorre em períodos de tempo relativamente mais curtos do que os de outros fluxos migratórios, e não seria, a priori, motivada por questões econômicas, mas por decisões pessoais que envolvem os aspectos socioculturais e condições de ensino (Nadine CATTAN, 2007; Louise ACKERS, 2004).

No campo das Ciências Sociais, o fenômeno da mobilidade discente internacional institucionalizada tem recebido, desde sua expansão, a partir da década de 1990, um tratamento teórico mais amplo, que abrange suas diversas facetas políticas, econômicas, sociológicas e psicológicas. Esse enfoque sociológico tem insistido, especialmente, no paradoxo entre "a tendência contemporânea crescente à internacionalização dos estudos nos diferentes graus do sistema de ensino" (Maria Alice NOGUEIRA, 2007, p. 18) e as desigualdades de acesso a esse bem educacional por parte dos diferentes grupos sociais.

\section{Mobilidade Acadêmica Institucionalizada: algumas políticas atuais}

Os estudos de Magali Ballatore e Thierry Blöss (2008b) definem, pelo menos, dois tipos de mobilidade: a "espontânea", na qual os estudantes escolhem individualmente se inscrever em uma instituição de ensino superior que não esteja localizada no seu país de origem, sem um acordo intergovernamental ou apoio institucional financeiro, e a "institucionalizada", ${ }^{4}$ como a mobilidade do estudante que se encontra previamente matriculado em uma instituição de ensino, constituindo-se de intercâmbios acadêmicos internacionais por meio de contratos entre organizações, podendo incluir, teoricamente, alguma reciprocidade. O Programa Ciência sem Fronteiras e o Erasmus $^{5}$ se inserem nesta última modalidade.

Algumas condições de possibilidade fazem com que um programa de intercâmbio tenha grande êxito. Na Europa, por exemplo, o Tratado de Bolonha, ${ }^{6}$ instituído pela União Europeia, consolidou-se em uma política abrangente de apoio à internacionalização do ensino superior, alçando o Erasmus como o maior programa de mobilidade acadêmica do mundo. Contudo, o próprio texto do tratado ressalta seu objetivo como uma estratégia de geopolítica:

Deve-se ter em conta o objetivo de elevar a competitividade internacional do sistema europeu de educação superior. A vitalidade e a eficiência de qualquer civilização podem medir-se pela atração que a sua cultura exerce sobre os outros países. Precisamos assegurar que o sistema europeu de educação superior consiga adquirir um grau de atração mundial semelhante ao da nossa extraordinária tradição cultural e científica (DECLARAÇÃO DE BOLONHA, 1999, p. 01).

Essa reforma universitária destinou-se à criação de um espaço de ensino superior europeu com equivalência em todos os países da Comunidade Europeia, propiciando e incentivando a circulação de estudantes por todo o continente.

No Brasil, a estrutura que deu suporte ao desenvolvimento da mobilidade internacional baseou-se em Políticas de Ensino Superior, Científica, Tecnológica e de Inovação (PCTI) reelaboradas nas últimas décadas, com o objetivo de atender às necessidades de desenvolvimento de novas tecnologias. Estas se inseriram na perspectiva dos novos ritos da economia global, gerenciadas por agências que financiam programas e ações de pesquisa e desenvolvimento (P\&D). Segundo Milena Y. Ramos (2018),

a mobilidade internacional é entendida como o principal mecanismo para impulsionar 0 intercâmbio científico e a colaboração em pesquisa, contribuindo para expandir seu perfil e impacto internacional. Essa visão é realizada por meio de um modelo ainda fortemente baseado numa "abordagem para o exterior", na qual a pesquisa está claramente no centro do processo de internacionalização.

O CsF, criado em meados do ano de 2011 (BRASIL, 2011),7 surge atrelado à dinâmica de desenvolvimento dos sistemas nacionais de aprendizado tecnológico, fundamentado na "absorção de tecnologias dos países industrializados por meio do processo de learning-by-doing", ${ }^{8}$ como confirma a pesquisadora Vânia Pereira $(2015$, p. 105).

\footnotetext{
${ }^{4}$ Também conhecida como organizada.

${ }^{5}$ European Region Action Scheme for the Mobility of University Students. Programa de intercâmbio estudantil europeu criado em 1987, que passou por grandes ampliações, sendo que em 2004 foi desdobrado em ERASMUS Mundus, com a finalidade de receber estudantes extraeuropeus. Mais de 4000 instituições de educação superior participam no Erasmus com 37 países envolvidos no programa Erasmus. Site do Programa: https://ec.europa.eu/programmes/ erasmus-plus/node_pt.

${ }^{6}$ O Tratado de Bolonha foi firmado em junho de 1999, na cidade italiana de Bologna.

7 O Programa foi criado por meio do Decreto 7692, durante o governo da Presidenta Dilma Rousseff

${ }^{8}$ Aprender fazendo (tradução livre).
} 
O Programa consistiu em atividades de cooperação internacional e na concessão de bolsas de estudos no exterior, operacionalizadas no âmbito da Coordenação de Aperfeiçoamento de Pessoal de Nível Superior (CAPES) e do Ministério da Educação (MEC), em parceria com o Conselho Nacional de Desenvolvimento Científico e Tecnológico (CNPq). A meta inicial era distribuir 101 mil bolsas, ao longo de quatro anos (2012-2015), para estudantes universitários de diferentes níveis: graduação, pós-graduação e estágio pós-doutoral. O maior número de bolsas foi reservado para a graduação, tendo restringido as bolsas às áreas de estudo consideradas "prioritárias", 9 distribuídas entre as ciências exatas, naturais e a tecnologia.

Alguns critérios foram relevantes para que as instituições de ensino pudessem se conveniar ao Programa, como, por exemplo, que fossem vinculadas à Rede Federal de Educação Superior e de Educação Profissional e Tecnológica ou pertencessem ao sistema estadual de educação superior paulista, incluindo as instituições públicas e privadas brasileiras com Índice Geral de Cursos (IGC) maior ou igual a quatro (INEP, 2013). ${ }^{10}$ Puderam ainda participar estudantes de instituições que tivessem IGC inferior a quatro, mas Conceito Preliminar de Cursos de Graduação (CPC) ${ }^{11}$ na área participante maior ou igual a quatro. A Capes estabelecera que, para participar do Programa, essas instituições deveriam apresentar propostas para os editais abertos pelo MEC, arrolando os cursos que pretendiam incluir. Após a avaliação, as universidades com suas propostas aprovadas receberam uma certa quantidade de bolsas. Atualmente, o Programa foi praticamente desativado, permanecendo com a oferta de bolsas para a pós-graduação.

\section{Metodologia \\ Tipo de Estudo}

Este artigo é fruto de uma pesquisa quantitativa, definida por Marcos Magalhães e Antonio Carlos Lima (2004) como aquelas expressas por "níveis de mensuração intervalar ou de razão, e que assumem valores numa escala métrica definida por uma origem e uma unidade" (p. 24). Os resultados são apresentados sob a forma de gráficos e tabelas que exibem a distribuição de estudantes bolsistas do Programa CsF. A elaboração dessa etapa se baseou na consulta de dados do painel de controle do Programa, dados do CNPq e COPEVE. A macroanálise, isto é, aquela que diz respeito a um contingente de pessoas muito abrangente, ocorre quando a pesquisa detecta dados em nível nacional. A microanálise ocorre estritamente quando aborda elementos característicos da população pesquisa.

\section{População da Pesquisa}

A população pesquisada consiste em um universo de 1538 estudantes dos cursos de graduação da UFMG, pertencentes a todas as áreas prioritárias, os quais se beneficiaram de bolsa do Programa CsF no ano de $2013^{12}$ (com término do intercâmbio previsto para 2014), em resposta aos editais da CAPES e do CNPq. ${ }^{13}$

\section{Procedimentos para a coleta de dados}

O planejamento da pesquisa empírica implicou a definição de duas frentes de trabalho para a coleta de dados. A primeira consistiu na coleta de dados secundários, em âmbito interno e externo. Os dados internos são provenientes da PROGRAD/COPEVE/UFMG, ${ }^{14}$ enquanto os externos provêm de duas fontes: do painel de controle do Programa CsF, disponível na internet, e do banco nacional de dados do CNPq. ${ }^{15}$ Este último documento possui o cadastro de todos os alunos beneficiados com a bolsa para participar do Programa CsF, no período de 2012 a 2013. Tratase de uma planilha que dispunha de nome, sexo, curso de origem, área prioritária, duração do intercâmbio, país e instituição de destino etc. dos estudantes da UFMG que ingressaram no CsF no ano de 2013 ( $N=1538)$, e que se tornaram o universo inicial de sujeitos.

\footnotetext{
9 Áreas Prioritárias do Programa CsF: Engenharias e demais áreas tecnológicas; Ciências Exatas e da Terra; Biologia, Ciências Biomédicas e da Saúde; Computação e Tecnologias da Informação; Tecnologia Aeroespacial; Fármacos; Produção Agrícola Sustentável; Petróleo, Gás e Carvão Mineral; Energias Renováveis; Tecnologia Mineral; Biotecnologia; Nanotecnologia e Novos Materiais; Tecnologias de Prevenção e Mitigação de Desastres Naturais; Biodiversidade e Bioprospecção; Ciências do Mar; Indústria Criativa (objetiva a criação de produtos e processos para desenvolvimento tecnológico e inovação); Novas Tecnologias de Engenharia Construtiva; Formação de Tecnólogos.

$10 \mathrm{O}$ IGC é um indicador de qualidade que avalia as instituições de educação superior calculado pelo Instituto Nacional de Estudos e Pesquisas Educacionais (INEP).

11 O CPC é um indicador de qualidade calculado pelo INEP, que avalia os cursos superiores.

12 No ano de 2013, o Programa executou as chamadas compreendidas entre 140 a 178 e, em 2014, executou

chamadas entre 179 a 204. Dados disponíveis pelo data mart do Programa.

${ }^{13}$ Informações disponíveis no site: http://www.cienciasemfronteiras.gov.br/web/csf.

14 Comissão Permanente do Vestibular da UFMG, órgão vinculado à Pró-Reitoria de Graduação.

${ }^{15}$ Documento cedido pela pesquisadora Alice Lopes.
} 


\section{A análise de dados}

Os dados provenientes do painel de controle do CsF e da planilha do CNPq possibilitaram o estudo comparativo do acesso de homens e mulheres ao Programa, bem como a estratificação dos pesquisados, por sexo, em cada área prioritária, dando origem às macroanálises relativas aos dados nacionais e da UFMG geral. Contudo, as análises mais estreitas, como a abordagem sobre o domínio da língua estrangeira, tiveram origem nos dados da COPEVE. Ressalta-se que esse órgão coleta os dados por curso, e que, nesse caso, coube à pesquisadora realizar os agrupamentos por área prioritária e, posteriormente, analisá-los.

Para fins de análise, os pesquisados foram divididos em grupos: o grupo da UFMG (todos os estudantes da UFMG); o grupo das Engenharias (todos os estudantes dessa área) e o grupo do CsF ( $\mathrm{N}$ da pesquisa). As engenharias constituíram o grupo de controle por ser a área que mais enviou estudantes ao CsF.

\section{Barreiras históricas, políticas necessárias e fronteiras que se refletem na mobilidade de mulheres}

Uma revisão sobre os estudos relacionados ao tema gênero e ciência revela que é preciso interrogar a relação entre gênero e ciência sob diversas dimensões. Estudo realizado por Lopes (2006) problematiza a historicidade dos estudos de gênero, analisando suas contribuições e limites para reflexões críticas sobre a construção das ciências, ao passo que Betina S. Lima e Maria da Conceição Costa (2016) adotam uma perspectiva de análise crítica sobre as contribuições das políticas científicas para a equidade de gênero no sistema científico e tecnológico implementadas no âmbito do Programa Mulher e Ciência. ${ }^{16}$ Segundo essas autoras,

o Programa Mulher e Ciência (PMC) é um marco nas questões de gênero, ciências e tecnologias. A institucionalização desse programa no âmbito do governo federal nos indica o reconhecimento por parte do Estado brasileiro, por meio dos seus inúmeros parceiros, da importância tanto de fortalecer os estudos sobre mulheres, relações de gênero e feminismos quanto de fomentar a participação feminina nas ciências. Esse reconhecimento aporta visibilidade ao tema da equidade de gênero na produção do conhecimento científico e tecnológico (LIMA; COSTA, 2016, p. 03).

De modo complementar, destaca-se estudo realizado por Minella (2013), a qual discute as temáticas prioritárias no campo de gênero e ciências no Brasil e problematiza a falta de estudos sobre outras dimensões que refletem as desigualdades no campo da ciência e que coloquem as relações de raça e etnia no centro das discussões. Segundo essa autora, trata-se de uma lacuna que se constitui em um desafio não apenas epistemológico, mas, principalmente, político. Contudo, Moema de Castro Guedes, Nara Azevedo e Luiz Otávio Ferreira (2015) interrogam a divisão sexual na produtividade científica, ao estudarem bolsistas de produtividade do CNPa. Para esses autores, o estudo revelou que a participação de homens e mulheres é proporcionalmente diferente entre as distintas áreas de conhecimento, assim como também concluem outros estudos citados mais à frente, neste trabalho. Para Estela Aquino (2006, p. 12), o tema gênero e ciência precisa ser compreendido a partir do estudo de, pelo menos, três dimensões: a primeira, visando desvendar o ingresso e o grau de participação das mulheres nos vários campos disciplinares, e conhecer as tendências históricas da atuação feminina, constitutivas de dados alienados em instituições e agências de fomento; a segunda, investigar as mudanças culturais no contexto de produção da ciência e do conhecimento, tendo como foco as relações de gênero, por meio da realização de estudos socioantropológicos; a terceira envolveria que o conteúdo do conhecimento produzido pelas mulheres fosse alvo de análises complexas de caráter epistemológico, histórico e sociológico. Entende-se que, neste estudo, contempla-se, direta e indiretamente, partes da primeira e segunda dimensões defendidas por Aquino (2006), visto que se coloca em evidência a participação feminina em um programa de formação para a ciência por meio de um processo de mobilidade acadêmica fomentado por agências públicas de pesquisa. Ao mesmo tempo, partese das prerrogativas dos estudos norteados pela perspectiva de Elisa Maria Saitovich, Betina Lima e Márcia Barbosa (2015), que reconhecem o aumento da participação feminina em diversas áreas do conhecimento, exceto na área da Física. Estudos realizados por Lucas B. Freitas e Nanci Stancky da Luz (2017) detectam algumas antinomias endossadas tanto por publicações que confirmam um número crescente de mulheres inseridas nos cursos de áreas científicas e tecnológicas, quanto apontam a ciência e a tecnologia como um espaço historicamente masculino. No Brasil, confirma-se um quadro de desigualdade histórica da participação de mulheres em alguns redutos da ciência. Esse fenômeno tem sido alvo de vários estudos. Destaca-se, nesse ponto,

\footnotetext{
16 Implementado em 2005, o Programa Mulher e Ciência (PMC) é resultado da parceria entre Ministério de Ciência, Tecnologia e Inovação (MCTI), Conselho Nacional de Desenvolvimento Científico e Tecnológico (CNPq), Secretaria de Políticas para as Mulheres (SPM), Ministério da Educação (MEC), Ministério de Desenvolvimento Agrário (MDA) e ONU Mulheres.
} 
aqueles realizados por Helena Maria Lastres, Hildete P. Melo, Teresa C. Marques (2004), Melo e Lastres (2006), Melo e André P. Oliveira (2006), Melo (2014), Melo e Lígia Maria Rodrigues (2006; 2018), que analisam a participação das mulheres na pesquisa registrada no âmbito do CNPq ou na base de dados do Scielo ${ }^{17}$ e lançam um olhar de gênero sobre o sistema de concessão de Bolsas de Pesquisa no CNPq.

Essas autoras e autor verificaram que as mulheres brasileiras predominam nas áreas de Ciências Humanas e Linguística, embora estejam bem representadas também nas áreas de Ciências Sociais e Aplicadas, Biológicas e da Saúde. No entanto, nas Ciências Exatas e da Terra, elas decaem um pouco, porém menos do que nas áreas Agrárias e nas Engenharias, áreas que como se sabe - são prioritárias no Programa CsF. Esse fenômeno, por sua vez, replica-se em outros contextos, sobretudo aqueles que priorizam as áreas das ciências exatas e a tecnologia, como é o caso do CsF.

Apesar dessas discrepâncias, os indicadores sobre a situação das mulheres no contexto educacional brasileiro revelam "maior presença feminina que masculina no ensino superior e melhor aproveitamento escolar das mulheres no ensino superior, que o dos homens" (Fúlvia ROSEMBERG; Leandro F. ANDRADE, 2008, p. 429). O Censo da Educação Superior realizado pelo INEP, no ano de 2013, indica que o número de estudantes matriculados no ensino superior do Brasil ultrapassa os sete milhões, sendo as mulheres a maioria entre os ingressantes $(54,7 \%)$, e entre concluintes $(59,2 \%)$.

As bolsas implementadas pelo CsF foram distribuídas de modo que $56 \%$ destas foram para estudantes do sexo masculino e o restante para as mulheres. A vantagem masculina é 12\% superior na obtenção de bolsas para a realização do intercâmbio proporcionado pelo CsF. Esses resultados seguem na contramão de várias estatísticas sobre a participação de homens e mulheres em programas de mobilidade no mundo, onde as mulheres têm predominado. Em 2000, $61 \%$ dos estudantes migrantes na Europa eram estudantes do sexo feminino, refletindo a realidade de um contexto em que, em todos os países europeus, na mesma década, 53\% dos estudantes matriculados no ensino superior eram mulheres, como afirma a estudiosa das relações de gênero nos intercâmbios europeus Cattan (2007). Trata-se de um aumento na proporção de mulheres nos cursos universitários.

Constitui um bom exemplo dessas estatísticas o programa Erasmus que, entre os anos de 2008 e 2012, exibiu uma média de participação feminina de 56,6\%, como informam os dados da Comissão Europeia em 2011. Ballatore (2008a) constata que, em todo o continente europeu, a mobilidade estudantil feminina atingiu o percentual de 68,7\% entre os anos 2004 e 2005, enquanto, nos Estados Unidos e Reino Unido, principais potências acolhedoras de estudantes móveis no mundo, essa vantagem feminina era de, respectivamente, 56\% e 55\%.

Cattan (2007) afirma que estudantes do sexo feminino são mais móveis. Estudos realizados pelo Registro de Alunos Inscritos e Diplomados do Ensino Superior (RAIDES) em Portugal apontam que os programas de mobilidade internacional no Ensino Superior em 2012/2013 contabilizaram em 58\% a participação da população feminina. Na Espanha, essa participação tem sido expressiva, pois elas somam $71 \%$ do percentual de estudantes que entrou em programas de mobilidade entre os anos de 2012/2013, e 62\% daqueles que já passaram por essa experiência, segundo Antônio Ariño et al. (2014). Diante desse contraste entre a presença feminina majoritária em programas de mobilidade estudantil em âmbito internacional e, minoritária, no CsF, cabe indagar se, ao privilegiar as "Engenharias e demais áreas tecnológicas", concedendo a essa área quase a metade, isto é, $45 \%$ do total de bolsas do Programa contabilizadas até agosto de 2015, o CsF refletiu o fenômeno apontado por Melo e Oliveira (2006): o de que as mulheres estão em menor número nas áreas das Engenharias. Contudo, para as pesquisadoras Rebeca Feltrin, Janaina Costa e Léa Velho (2016), em estudo realizado uma década depois desse último, a presença de mulheres em todas as modalidades de bolsas de formação no CsF foi evidenciada como significativa, o que pode ser considerado um importante contraponto analíitico quando se considera o cenário histórico preexistente sobre a presença das mulheres no contexto da Ciência e Tecnologia. No entanto, as diferenças ainda persistem, revelando desigualdades na distribuição de bolsas entre as áreas prioritárias, como se vê na Tabela 1, a seguir.

Tabela 1 - Distribuição dos estudantes do CsF por sexo e área prioritária - População nacional

\begin{tabular}{|c|c|c|}
\hline ÁREAS PRIORITÁRIAS & $\begin{array}{c}\text { Percentual Geral de } \\
\text { estudantes }\end{array}$ & $\begin{array}{c}\text { Percentual de } \\
\text { Mulheres }\end{array}$ \\
\hline Engenharias e demais áreas tecnológicas & $45 \%$ & $34 \%$ \\
\hline Biologia, Ciências Biomédicas e da Saúde & $17 \%$ & $62 \%$ \\
\hline Indústria Criativa & $9 \%$ & $65 \%$ \\
\hline
\end{tabular}

17 O SciELO, criado em 1997, é uma livraria eletrônica que agrupa muitos periódicos nacionais e internacionais, além de uma coleção de títulos individuais. 


\begin{tabular}{|c|c|c|}
\hline Ciências Exatas e da Terra & $8 \%$ & $41 \%$ \\
\hline Computação e Tecnologias da Informação & $6 \%$ & $5 \%$ \\
\hline Produção Agrícola Sustentável & $3 \%$ & $49 \%$ \\
\hline Biotecnologia & $2 \%$ & $59 \%$ \\
\hline Fármacos & $2 \%$ & $69 \%$ \\
\hline Biodiversidade e Bioprospecção & $1 \%$ & $52 \%$ \\
\hline Energias Renováveis & $2 \%$ & $42 \%$ \\
\hline Outras & $4 \%$ & $48 \%$ \\
\hline Total & $\mathbf{1 0 0} \%$ & \\
\hline
\end{tabular}

Fonte: Elaboração própria a partir de dados disponibilizados pelo Data mart do CsF até agosto de 2016. Nota: $\mathrm{Nl}=$ Não informado.

\#PraTodoMundoVer A tabela mostra as áreas prioritárias do Programa Ciência sem Fronteiras com as seguintes informações e na seguinte sequência: identificação da área prioritária, percentual geral de estudantes e percentual de mulheres em cada área: Engenharias e demais áreas tecnológicas $45 \%$ e 33\%, Biologia, Ciências Biomédicas e da Saúde 17\% e 62\%, Indústria Criativa 9\% e 65,0\%, Ciências Exatas e da Terra $8 \%$ e $41 \%$, Computação e Tecnologias da Informação 6\% e 5\%, Produção Agrícola Sustentável 3\% e $49 \%$, Biotecnologia 2,0\% e 59\%, Fármacos $2 \%$ e $69 \%$, Biodiversidade e Bioprospecção $1 \%$ e $52 \%$, Energias Renováveis $2 \%$ e $42 \%$, e outras com $4 \%$ e $48 \%$.

A Tabela 1 mostra os dados do CsF desagregados por áreas prioritárias e possibilita observar que as "Engenharias e demais áreas tecnológicas" têm o maior número de bolsistas no Programa, tanto entre a população masculina quanto feminina. Nota-se que, enquanto eles são maioria nas áreas de Ciências Exatas e da Terra, Computação e Tecnologias da Informação, elas predominam na Biologia, Ciências Biomédicas e Ciências da Saúde, Indústria Criativa e Fármacos. Além do mais, se o CsF tivesse distribuído um número maior de bolsas para a área de Ciências Biológicas, Biotecnologia e Saúde, o cenário tenderia a ser mais equilibrado. Corroborando esse entendimento, Feltrin, Costa e Velho (2016) assinalam que as áreas biológicas e de saúde contam hoje com presença igualitária ou até majoritária de mulheres; as demais áreas prioritárias no CsF são tipicamente "masculinas" (p. 05). Contudo, com relação aos dados relacionados à Ciência da computação, convém lembrar o estudo de Juliana Schwartz et al. (2006) sobre o pioneirismo das mulheres que se dedicaram à informática e marcaram o desenvolvimento dessa área do conhecimento e da sociedade como um todo. Os dados da Tabela 1 evidenciam a perda de espaço de ocupação das mulheres nessa área. Corroborando essa perspectiva, um estudo recente realizado por Marcel Maia (2016) detectou que, no período de 2000 a 2013, o número de concluintes homens na área de computação cresceu $98 \%$, enquanto o de concluintes mulheres decresceu $8 \%$. Para esse estudioso, trata-se de um "fenômeno raro no ensino superior brasileiro, mesmo se comparado aos campos de tradicional presença masculina, como o da engenharia" (p. 241). O teto de vidro mencionado por Maria Rosa Lombardi (2006) nas carreiras femininas de ciência e tecnologia, em que se observa a presença feminina em certas áreas, decorre de preconceitos por parte da família e da sociedade, e da falta de perspectiva no mercado de trabalho (LOMBARDI, 2006, p. 130). Segundo Rosemberg e Andrade (2008), as mulheres tendem a seguir carreiras ligadas à área de Humanidades como o magistério, consideradas menos prestigiosas do que as ocupações exercidas por homens. Os estudos de Aquino (2006) e Melo e Lastres (2006) atestam que, no Brasil, as áreas representadas pela Matemática, Física e Engenharias tendem a atrair poucas mulheres. Entretanto, a incorporação das mulheres em atividades científicas pode ser confirmada desde 1997, entre pesquisadores e líderes de Grupos de Pesquisa cadastrados na base Lattes do CNPq: nestes dois subgrupos, a proporção de mulheres, em 2002, era respectivamente de 45,7\% e 40,7\% (Jacqueline LETA; Grant LEWISON, 2003, p. 345). Também Aquino (2005, p. 150) aponta que elas "estão mais concentradas em algumas áreas, tais como as Ciências da Saúde $(54,7 \%)$ e as Ciências Biológicas (51,9\%), além das Ciências Humanas $(60,0 \%)$ ".

Essa tendência parece ocorrer também no exterior, pois, de acordo com Ballatore (2008a), no quadro do Erasmus, as mulheres estão concentradas nas áreas de Linguagem, Ciências Humanas, Ciências Sociais e Ciências Naturais, enquanto os homens são maioria nas áreas de Matemática e Engenharia.

No entanto, a tese de que as mulheres vêm adentrando nesses espaços tipicamente masculinos tem sido sustentada por alguns pesquisadores, como Lombardi, que tem realizado estudos sobre a participação das mulheres no campo das Engenharias. Essa pesquisadora traça uma linha histórica desde 1991, quando as mulheres detinham o percentual de 16,4\%, tendo crescido para 20\% em 2002 (LOMBARDI, 2006). Ela acredita que a formação do público feminino, não apenas em engenharias e exatas, mas em todas as áreas de Ciência e Tecnologia, tem crescido em ritmo lento, porém, contínuo. Para essa autora, a escolha das mulheres pela carreira 
da engenharia é parte de um processo que vem evoluindo, como no caso da Escola Politécnica da Universidade de São Paulo em que, entre 1950 e 1989, isto é, um longo hiato de 39 anos, formaram-se, apenas, 536 engenheiras, enquanto, nos anos 1990, essa quantia subiu para 764.

Por sua vez, Helena Hirata (2002), há 18 anos, já assinalava que a área das engenharias vinha apresentando um aumento paulatino da atividade feminina, embora a decisão de entrar em um curso de engenharia ainda significasse, para a mulher, entrar em território masculino. Para Marília G. Carvalho (2008), entre os anos de 2000 e 2005, houve um crescimento pequeno, mas progressivo, da participação das mulheres nessas áreas tradicionalmente reconhecidas como masculinas, embora ainda se perceba "uma quase total invisibilidade das mulheres neste domínio" (p. 22).

\section{O Programa CsF na UFMG}

A UFMG, por meio de sua Diretoria de Relações Internacionais (DRI), promoveu ações de divulgação do Programa CsF, prestando esclarecimentos sobre editais e instituições conveniadas. Ressalta-se que, por se tratar de uma instituição experiente na promoção de intercâmbios, havia uma estrutura e uma logística interna que possibilitaram que a UFMG se destacasse no envio de alunos ao exterior. Ao todo, a UFMG enviou 4336 alunos ao Programa CsF, em torno de 9,0\% do total de alunos matriculados. ${ }^{18} \mathrm{~A}$ maior parte desses estudantes era da graduação, ${ }^{19}$ e o restante, ${ }^{20}$ da pós-graduação.

É importante ressaltar que as instituições públicas federais assumiram a dianteira nesse processo. De acordo com informações do próprio Programa, nove em cada dez universitários brasileiros que receberam uma bolsa até dezembro de 2013 estavam vinculados a instituições e órgãos públicos. Quanto às áreas prioritárias predominantes, destacaram-se as "Engenharias e demais áreas tecnológicas", com o maior número de beneficiários, seguida da área de "Biologia, Ciências Biomédicas e da Saúde". As primeiras posições como opção de destino foram daqueles países tradicionalmente procurados para essa finalidade, com destaque para os EUA e o Reino Unido.

Os estudantes da UFMG beneficiados pelo Programa CsF dividiram-se em 58\% masculino e $42 \%$ feminino. Portanto, nessa instituição, o público masculino obteve a vantagem de $16 \%$ sobre as mulheres. Dentre as modalidades de formação oferecidas pela UFMG, a graduação enviou em torno de $85 \%$ ao CsF, seguida por uma pequena parcela da pós-graduação, composta pelo Doutorado Sanduíche, Doutorado Pleno e Pós-Doutorado com 14\% e as demais modalidades perfazendo apenas $1 \%$ dentre os beneficiários do Programa.

Gráfico 1 - Distribuição de bolsas CsF na UFMG por Área Prioritária

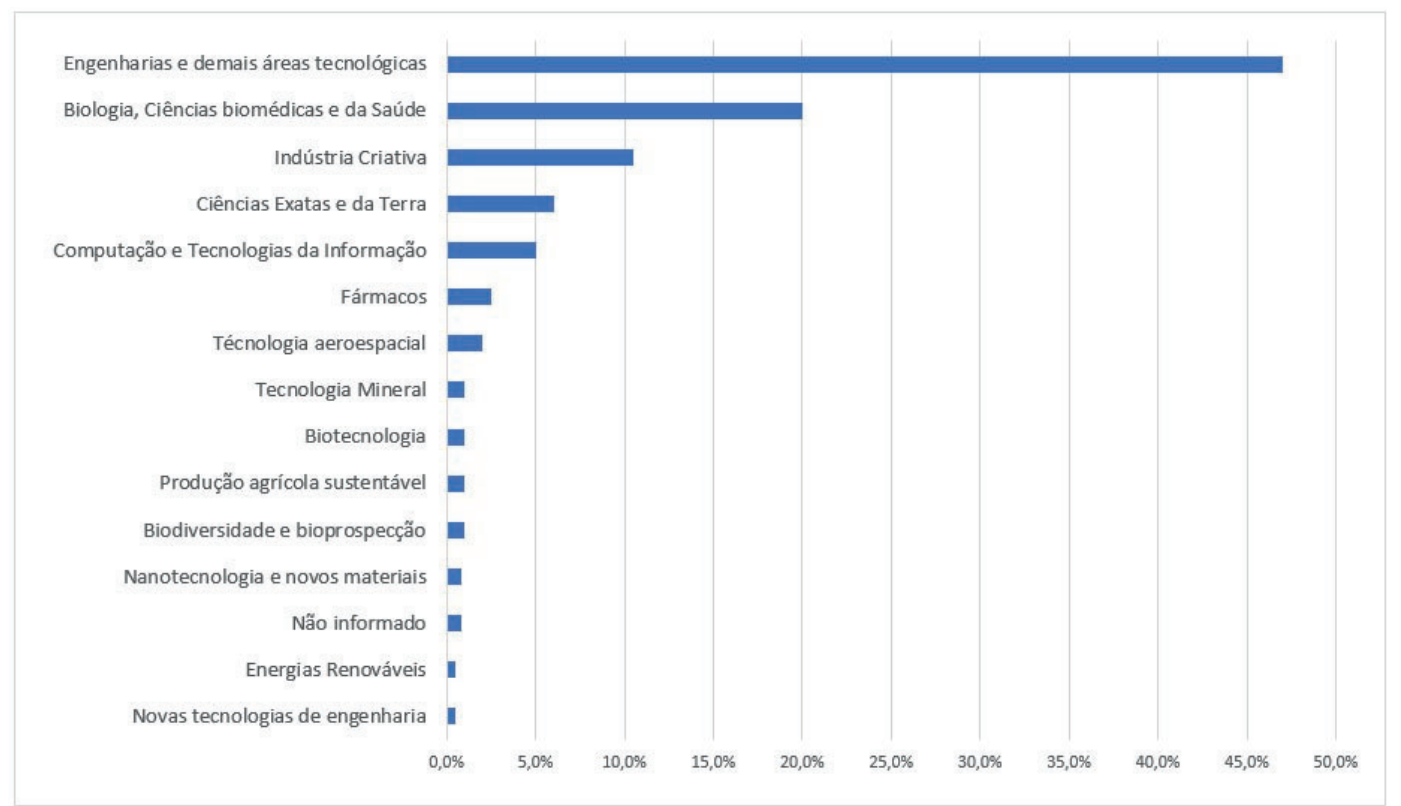

Fonte: Elaboração própria a partir de dados disponibilizados pelo Data mart do CsF até agosto de 2016.

\#PraTodoMundoVer $\mathrm{O}$ gráfico mostra barras horizontais que representam a distribuição de bolsas do Programa Ciência sem Fronteiras por Área Prioritária na Universidade Federal de Minas Gerais. O gráfico está

${ }_{18}$ A UFMG ocupou o primeiro lugar em Minas Gerais e o segundo do País no envio de estudantes para o exterior durante a vigência do Programa Ciência sem Fronteiras.

$1985 \%$ de 4098.

$2015 \%$ de 4098 . 
enumerado de acordo com percentuais que vão de zero a cinquenta por cento. As Engenharias e demais áreas tecnológicas estão representadas por uma barra horizontal que alcança $48 \%$ dos estudantes. A Biologia, Ciências Biomédicas e da Saúde estão representadas por uma barra horizontal que totaliza $20 \%$ dos estudantes. A Indústria Criativa está representada por uma barra que alcança $11 \%$ dos estudantes. As Ciências Exatas e da Terra estão representadas por uma barra que alcança em torno de 7,5\% dos estudantes e a Computação e Tecnologias da Informação estão representadas por uma barra que alcança 6\% dos estudantes. A área de Tecnologia Aeroespacial está representada por uma barra que alcança $2 \%$ dos estudantes. As demais áreas estão representadas por barras horizontais que totalizam em torno de $7 \%$.

Quanto às áreas prioritárias predominantes entre os estudantes enviados pela UFMG para o intercâmbio do CsF, observou-se que estas refletem a mesma hierarquia presente nos dados gerais do Programa, visto que predominam as "Engenharias e Demais Áreas Tecnológicas", com mais do que o dobro do que a área que aparece em segundo lugar, conforme o Gráfico 1, acima. Esclareça-se que essa é uma área muito extensa e, no caso da UFMG, engloba 14 cursos de engenharia, sem contar os cursos que oferecem formação tecnológica. Em relação à segunda área, apesar de muito grande também, contando com 12 cursos, há especificidades que podem interferir no intercâmbio, como ocorre com o curso de medicina, em função do ciclo clínico que se inicia no $5^{\circ}$ período, dificultando a incursão em pesquisas, além de ter uma estrutura curricular muito específica. Embora estratégicas, as áreas menos preenchidas são aquelas que apresentam um número reduzido de cursos de graduação ou que estão restritas a microáreas específicas dentro de um curso ou programa de pesquisa.

Gráfico 2 - Distribuição dos estudantes por sexo na UFMG geral, nas engenharias e na população da pesquisa em 2013

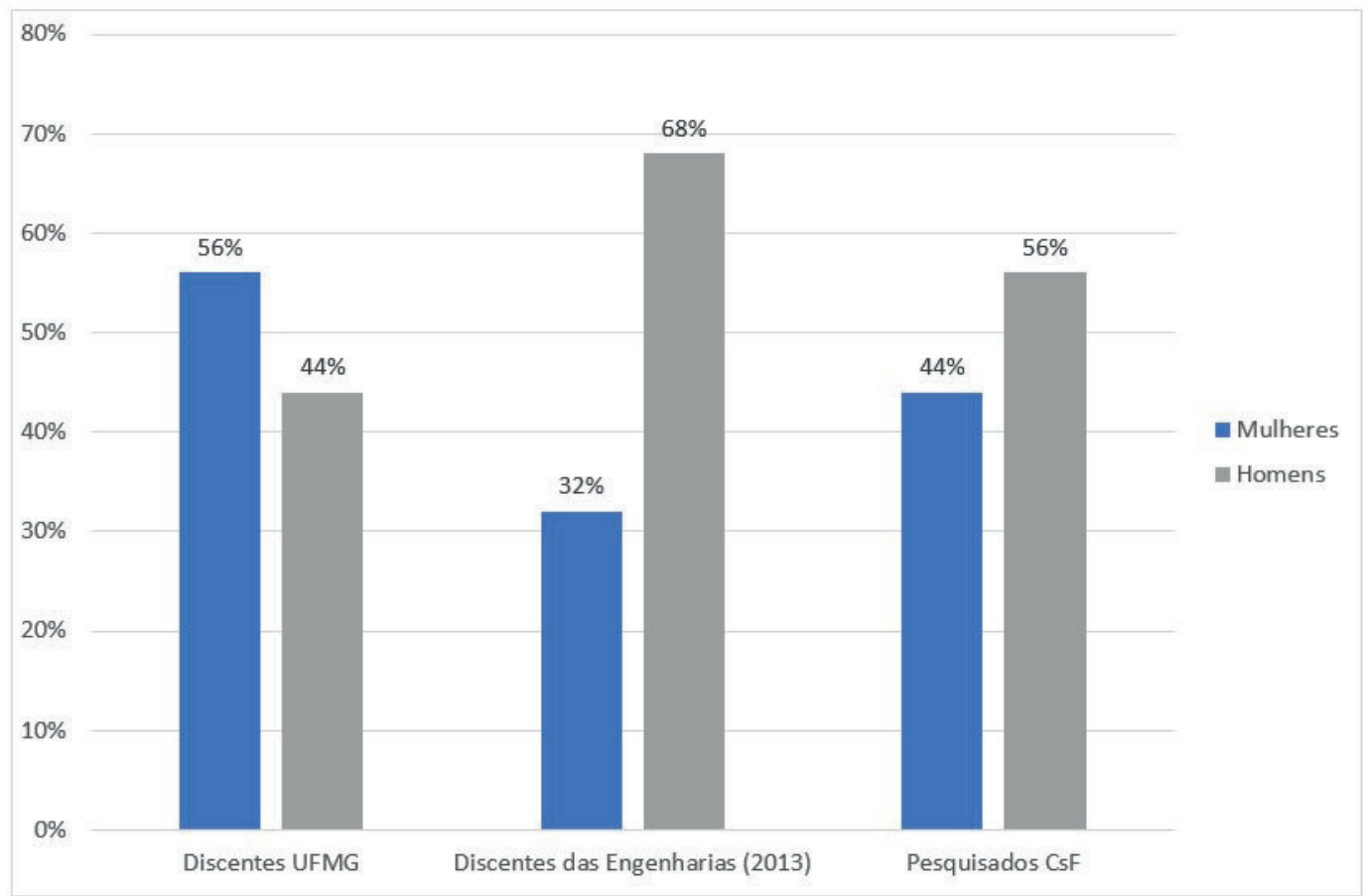

Fonte: Elaboração própria a partir de dados da pesquisa.

\#PraTodoMundoVer $\mathrm{O}$ gráfico mostra barras verticais que representam três eixos intitulados: Discentes da UFMG, Discentes das Engenharias em 2013, Pesquisados do CsF. O percentual total das colunas consta de 0\% a $80 \%$. O primeiro eixo que representa o número de discentes da UFMG no ano de 2013 tem duas colunas, sendo que a primeira representa $56 \%$ e a segunda coluna $44 \%$. O segundo eixo do gráfico também tem duas colunas que comparam a presença de discentes homens e mulheres nas áreas das engenharias na UFMG. A primeira coluna representa as mulheres com $32 \%$, enquanto a segunda coluna representa os homens, com $68 \%$. O terceiro eixo é composto por duas colunas que comparam a presença de homens e mulheres entre os pesquisados, sendo que há $44 \%$ de mulheres e $56 \%$ de homens.

Nota-se que há um percentual maior de mulheres na área prioritária das engenharias no CsF do que nas engenharias em geral, conforme se observa no Gráfico 2. Essa constatação parece estar relacionada a uma desigual distribuição das bolsas, que pode ter sido maior para as áreas mais tradicionalmente masculinas. Portanto, proporcionalmente, haveria mais mulheres no CsF do que na área de origem, porque houve mais bolsas para as Engenharias.

Quanto aos dados do segundo grupo, isto é, discentes das Engenharias, embora demonstrem uma relação, ainda, bastante desigual entre a presença de homens e mulheres 
nessa área, convém destacar que, de acordo com estudos recentes realizados por Mônica M. Bahia e João Bosco Laudares (2011) sobre a participação das mulheres em áreas específicas das engenharias da UFMG, entre os anos de 2004 e 2009, houve um aumento gradativo do número de mulheres inscritas em todos os cursos de engenharia dessa universidade, sendo que os mais procurados por elas foram: a Engenharia Civil, seguida da Engenharia Química, da Engenharia de Produção e da Engenharia Ambiental. Dentre os menos procurados, situam-se a Engenharia Mecânica e Engenharia Elétrica, redutos masculinos mais tradicionais.

Certamente, a maior procura de mulheres pelas Engenharias está relacionada a alguns fatores, tais como: o aumento de mulheres no Ensino Superior, a criação de novos cursos nessa área e, culturalmente, as mudanças de alguns estereótipos que, segundo Lombardi (2006), "contribuíram para mantê-las fora da engenharia como um todo [...] mas que têm sido questionados socialmente e, em consequência, perderam parte de seu poder de intimidação" (LOMBARDI, 2006, p. 200). No entanto, convém observar alguns percentuais observados neste estudo, como evidencia a ilustração seguinte.

Gráfico 3 - Distribuição dos pesquisados, por sexo e por área prioritária, na UFMG, 2013

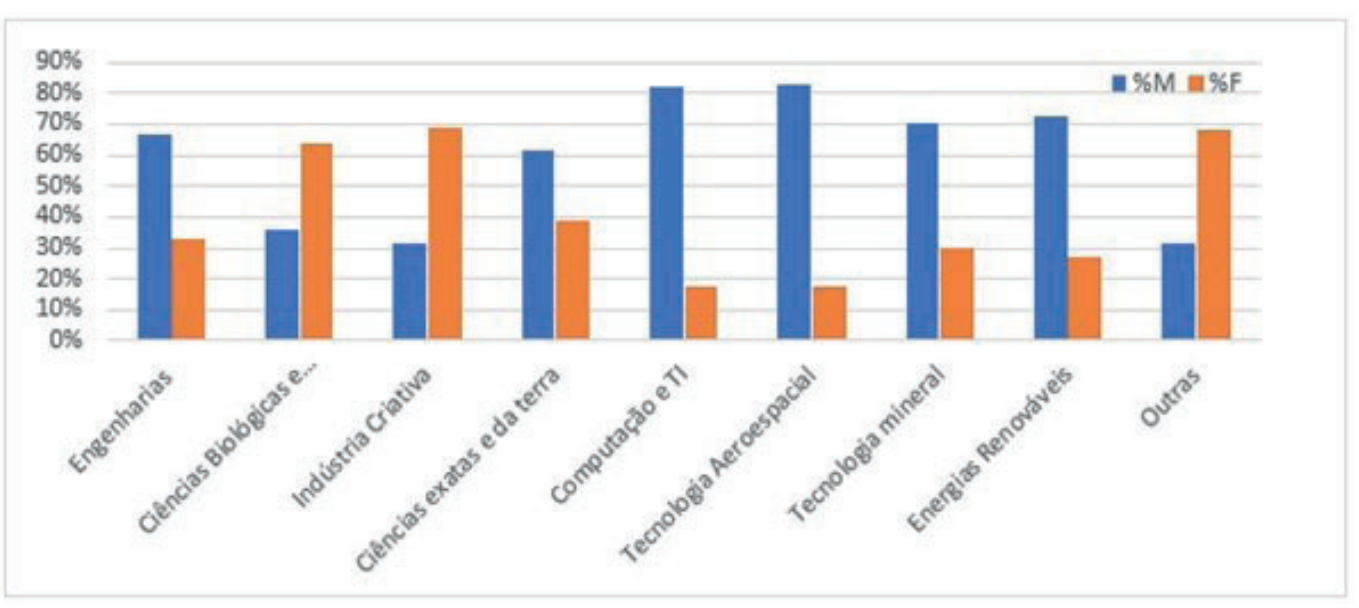

Fonte: Elaboração própria a partir de dados da pesquisa.

\#PraTodoMundoVer O gráfico mostra a distribuição dos pesquisados por sexo e por área prioritária na UFMG em 2013. O percentual das colunas vai de 0 a $90 \%$. São nove eixos no total, sendo que cada eixo é composto por duas colunas. A primeira coluna se refere ao percentual de homens e a segunda coluna se refere ao percentual de mulheres. O primeiro eixo compara o percentual de homens e mulheres nas Engenharias. Sua primeira coluna representa $67 \%$ de homens frente a $33 \%$ de mulheres. O segundo eixo compara dados da área de Ciências Biológicas e da Saúde; a primeira coluna representa $35 \%$ de homens e a segunda $65 \%$ de mulheres. O terceiro eixo trata da área de Indústria Criativa, revelando, na primeira coluna, 31\% de homens frente a $69 \%$ de mulheres. O quarto eixo representa a área das Ciências Exatas e da Terra, e sua primeira coluna representa $61 \%$ do percentual de homens, frente a $39 \%$ do percentual de mulheres na segunda coluna. $O$ quinto eixo informa sobre dados da área de Computação e Tecnologias da Informação e é composto por um percentual de $82 \%$ de homens na primeira coluna frente a $18 \%$ de mulheres, respectivamente. A sexta área é a Tecnologia Aeroespacial e sua primeira coluna representa $82 \%$ de homens frente a $18 \%$ de mulheres na segunda coluna. A sétima área é a tecnologia mineral e sua primeira coluna representa $70 \%$ de homens, enquanto, a segunda coluna, 30\% de mulheres. A oitava área é Energias Renováveis, composta pela primeira coluna, com $72 \%$ de homens frente a $28 \%$ de mulheres, e o nono eixo é denominado de eixo e representa um conjunto de áreas pouco representativas no CsF, também composto por duas colunas; a primeira representa dados sobre os homens, totalizando $31 \%$, frente a um percentual maior de mulheres, $69 \%$.

Como se pode observar no Gráfico 3, as áreas que concentram maior número de mulheres são aquelas relacionadas às Ciências Biológicas e da Saúde, além da Indústria Criativa. As demais áreas concentram mais estudantes do sexo masculino, corroborando, ainda, a predominância de homens nas áreas relacionadas às Exatas. Tais dados confirmam as análises realizadas por Melo e Lastres (2006) e de pesquisa realizada por Sileide F. T. Salvador (201 1), que afirma que são poucas, muito poucas, as mulheres presentes nas profissões ligadas à tecnologia e à produção, em especial nos cursos de engenharia. No que concerne à área de Computação, o estudo de Maia (2016) concorda com essa análise.

A coordenadora do Núcleo de Estudos e Pesquisas sobre a Mulher (Nepem) da UFMG, Marlise Matos, afirma que o maior número de alunas na UFMG segue uma tendência mundial que indica um percentual maior de mulheres em todos os níveis do ensino, porém distribuído de forma desigual entre os diferentes cursos. Para essa especialista da UFMG, o desafio é superar as barreiras de atuação para homens e mulheres, rompendo com alguns estereótipos de gênero associados a algumas áreas de formação e carreiras. 
Como o CsF é um Programa de mobilidade que exige proficiência em língua estrangeira, esse pressuposto teria que ser analisado a fim de verificar se esta seria a causa da menor participação feminina. Teriam as mulheres uma proficiência linguística ${ }^{21}$ inferior à de seus colegas masculinos? Para responder a essa questão, analisou-se a proficiência linguística entre homens e mulheres matriculados na UFMG e nas Engenharias em 2013, comparando-os aos pesquisados, tendo em vista que o domínio de um segundo idioma segue critérios eliminatórios para a seleção do Programa e poderia justificar uma menor participação de mulheres no CsF.

Gráfico 4 - Nível de proficiência em leitura em língua estrangeira, por sexo, informado pelos discentes da UFMG, das engenharias e do CsF em 2013

Fonte: Elaboração própria a partir de dados da pesquisa.

\#PraTodoMundoVer $\mathrm{O}$ gráfico mostra $\mathrm{O}$ nível de proficiência, em língua estrangeira, de alunos da UFMG distribuídos por sexo, em três grupos dentro do percentual de proficiência de 0 a $90 \%$. O gráfico está representado por seis eixos, com quatro colunas cada. A primeira coluna de cada eixo representa o nível de capacidade de leitura em inglês. A segunda coluna representa o nível de leitura em duas línguas. A terceira coluna representa o nível de leitura em língua espanhola e a última coluna representa dados sobre aqueles ou aquelas que não leem nenhuma língua estrangeira. O primeiro eixo é composto por dois grupos de quatro

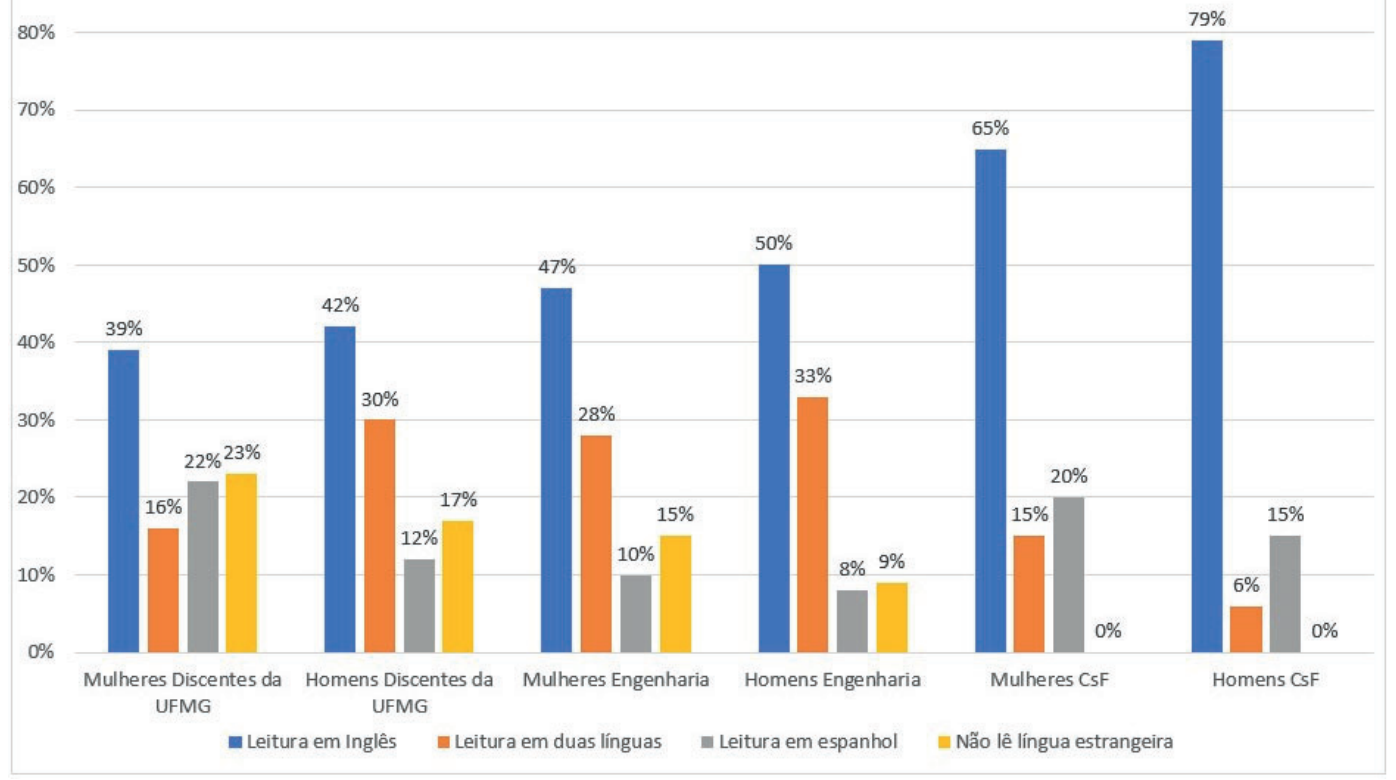

colunas cada, sendo que o primeiro grupo representa as mulheres discentes da UFMG e o segundo grupo representa os homens discentes da UFMG. Nesse primeiro eixo, a primeira coluna indica que $39 \%$ das mulheres afirmam capacidade de leitura em inglês, e a segunda coluna mostra que $16 \%$ delas afirmam ler em duas línguas, enquanto a terceira coluna indica $22 \%$ de mulheres que leem língua espanhola frente a $23 \%$ que não leem nenhuma língua estrangeira. O segundo grupo possui quatro colunas referentes aos dados sobre homens discentes da UFMG. A primeira coluna desse eixo mostra que $42 \%$ desses homens afirmam capacidade de leitura em inglês, enquanto na segunda coluna $30 \%$ afirmam que leem duas línguas, e na terceira coluna, $12 \%$ afirmam que leem língua espanhola frente a $17 \%$ que não leem nenhuma língua estrangeira. O segundo eixo também é composto por dois grupos de colunas que representam dados de homens e mulheres da área de Engenharia. Na primeira coluna que representa $\circ$ grupo de mulheres, $47 \%$ destas afirmam que leem inglês como língua estrangeira. Na segunda coluna, $28 \%$ delas afirmam que leem em duas línguas, enquanto na terceira coluna 10\% afirmam que leem língua espanhola frente a $15 \%$ que afirmam não lerem em nenhuma língua estrangeira. No segundo grupo composto por colunas que informam dados acerca dos homens, 50\% deles afirmam que leem a língua inglesa, sendo que na segunda coluna $28 \%$ deles afirmam que leem em duas línguas e $8 \%$ afirmam que leem em língua espanhola, enquanto $9 \%$ não leem nenhuma língua estrangeira. $\bigcirc$ terceiro eixo tem quatro colunas que apresentam dados dos participantes da pesquisa, bolsistas do Programa Ciência sem Fronteiras. A primeira coluna do primeiro grupo indica que $65 \%$ das mulheres que participaram do Programa afirmam que leem em língua inglesa e a segunda coluna desse mesmo grupo indica que $33 \%$ das mulheres que participaram do Programa afirmam que leem em duas línguas estrangeiras. A terceira coluna indica que $20 \%$ delas leem em língua espanhola. A primeira coluna do segundo grupo, referente aos homens, indica que $79 \%$ deles afirmam que leem em língua inglesa, e a segunda coluna indica que $6 \%$ deles afirmam que leem em mais de uma língua estrangeira. Já 15\% deles afirma que leem em língua espanhola. Nesse eixo, nos dois grupos, ninguém informou falta de proficiência em língua estrangeira.

A análise do Gráfico 4 mostra que, entre os matriculados na UFMG, em 2013, é pouco significativa a diferença entre homens e mulheres quanto ao grau de proficiência linguística

${ }^{21}$ Nesta fase, apenas o nível de leitura foi analisado em função dos dados disponibilizados pela COPEVE/PROGRAD. 
informada, pois, enquanto os homens informam maior domínio de leitura em duas línguas estrangeiras, elas o superam em relação à proficiência em língua espanhola. No contexto dos matriculados em Engenharia, o nível de proficiência em língua estrangeira informado é maior em relação ao conjunto, entretanto, nota-se que as diferenças entre homens e mulheres diminuem em relação à leitura em dois idiomas, pois enquanto eles se mantêm em torno de $32 \%$, elas alcançam $28 \%$, superando os $15 \%$ informados pelos estudantes totais. No que concerne aos pesquisados, há um equilíbrio entre a proficiência informada, sendo que 14\% a mais entre os homens informam maior domínio de leitura em inglês enquanto elas os superam em $9 \%$ tanto na proficiência em dois idiomas, quanto em 5\% na língua espanhola. Portanto, não foram detectados problemas em relação à proficiência linguística que justificassem que houvesse mais de 33\% a mais de homens no CSF na área das Engenharias e outras tecnologias. Os demais dados analisados na pesquisa não permitiram outra conclusão, senão a de que o número menor de mulheres na referida área prioritária do CsF deveu-se a uma questão proporcional, como já argumentado anteriormente.

\section{Conclusão}

Este artigo começa interrogando o acesso igualitário das mulheres ao Programa Ciência sem Fronteiras, tomando como pressuposto a tradição do pensamento já constituído acerca das desigualdades de gênero. Como resultado, apresentam-se dados que evidenciam que o número de mulheres no Programa é menor do que o de homens. Não chega a ser um absurdo estatístico, e até mesmo corrobora vários estudos citados ao longo do texto, de que as mulheres ainda não alçaram à igualdade, mas as estatísticas teriam melhorado - como demonstrado em alguns estudos citados no corpus deste trabalho -, embora ainda sejam negativas. Não se trata de não celebrar conquistas, as quais são bastante significativas, talvez graças a mais políticas voltadas para as mulheres na ciência, sobretudo na primeira metade da última década, como é o caso do Programa Mulher e Ciência.

O fato de que menos mulheres foram para o exterior para estudar pelo Programa CsF é muito significativo porque reflete as desigualdades de gênero; significa, sobretudo, que menos mulheres se valeram de uma oportunidade sociocultural, foram negligenciadas no sentido de não poderem obter um bem cultural, profissional e academicamente valorizado. Muitas vezes, podese dizer, com base na literatura consultada, em função de arquétipos culturais que fragilizam a mulher diante dos campos das ciências exatas, bem como se baseiam em essencialismos que as despotencializam diante das possibilidades.

Então, surge uma nova questão, uma inquietante necessidade de compreender a diferença de participação de homens e mulheres no CsF. Um olhar desinteressado pelas relações de gênero talvez não notasse. Afinal, elas são apenas 12\% a menos que os homens em âmbito nacional. No interior da UFMG, principalmente, a desigualdade manifestou-se maior. 16\% menos mulheres no CsF. Quem sabe ecoariam rompantes: as mulheres estão chegando lá! Quiçá, observariam como normalidade, assim como as demais "normalidades" que pululam em torno das questões de gênero na sociedade. Porém, um(a) pesquisador(a) inquietado não é um desinteressado; ele é, antes, afetado pela dúvida, pela necessidade de interrogar, sem aquiescer, a objetividade dos cálculos como um dogma.

Portanto, é a essa inquietação que este artigo responde. Após as análises dos dados e da correlação com outras pesquisas, observou-se que os resultados evidenciaram uma correspondência proporcional entre as desigualdades presentes nas ciências exatas e o menor número de mulheres no Programa CsF. O fato de essa área ser privilegiada pelo Programa provavelmente se refletiu nas estatísticas desfavoráveis às mulheres. Evidenciou-se que, em comparação aos dados do Erasmus, e alguns dados isolados de países europeus, o Programa brasileiro se mantém aquém das estatísticas no que concerne ao envio de mulheres para o intercâmbio. No entanto, o programa europeu não se restringe a algumas áreas, corroborando alguns pressupostos teóricos citados de que a prioridade dada às exatas impactou os resultados brasileiros. Tanto no Brasil quanto na Europa, os números mostram avanços contínuos das mulheres na área acadêmica. Contudo, pelo menos no Brasil, elas permanecem segregadas às mesmas áreas do passado, embora se admitam alguns avanços.

Suspeitou-se que a proficiência linguística poderia ser um problema inibidor da maior participação feminina no acesso à mobilidade internacional, por ser esse um dos principais requisitos para o intercâmbio. No entanto, essa suspeita foi superada pelas análises, que mostraram não haver diferenças desproporcionais entre homens e mulheres nesse quesito. A conta fica mesmo para a divisão sexual das áreas científicas.

A fim de concluir, é preciso ressaltar alguns pontos importantes: a) não há razões para o desânimo, visto que as pesquisas que fundamentaram as análises atestam que o número de mulheres é maior no ensino superior e que elas não apenas se matriculam, mas concluem seus estudos em número maior que o dos homens, então essa dinâmica tende a mudar; b) as engenharias, embora aquelas mais tradicionais ainda tenham um número menor de mulheres, 
vêm mudando e aumentando gradativamente o número de mulheres; c) é preciso que os estudos sobre essas diferenças afetem as políticas públicas, promovendo ações para a redução dessas desigualdades, que haja interessados em desvendar as anormalidades; d) outros estudos poderiam contribuir para que se detectasse o perfil sociológico das mulheres que foram para o Programa, de modo a desvendar as relações sociais implicadas na obtenção do benefício.

\section{Referências}

ACKERS, Louise. "Managing relationships in peripatetic careers: Scientific mobility in the European Union". Women's Studies International Quarterly, v. 27, n. 3, p. 189-201, 2004.

AQUINO, Estela Maria. "Gênero e saúde: perfil e tendências da produção científica no Brasil". Revista de Saúde Pública, São Paulo, v. 40, n. Esp., p. 121-132, 2006.

ARIÑO, Antônio; SOLER Ignés; LLOPIS, Ramon. "La Movilidad Estudiantil en España". Revista de la Asociación de Sociología de la Educación, v. 7, n. 1, p. 143-167, 2014.

BAHIA, Mônica M.; LAUDARES, João Bosco. "A participação das mulheres em áreas específicas da Engenharia". In: CONGRESSO BRASILEIRO DE EDUCAÇÃO EM ENGENHARIA, XXXIX, 201 1, Blumenau, FURB. Anais... Blumenau: FURB, 2011. p. 1-9.

BALLATORE, Magali; BLÖSS Thierry. "Láutre réalité du programme Erasmus: affinités elective entre établissements et reproduction sociale des étudiants. "Formation Emploi, n. 103, p. 57-74, 2008 a.

BALLATORE, Magaly; BLÖSS, Thierry. "Le sens cache de la mobilité des étudiants Erasmus". In: DERVIN, Fred; BYRAM, Mike (Dirs.). Échanges et mobilités académiques. Quel bilan? Paris: Éditions L'Harmattan, 2008b. p. 17-31.

BRASIL. Decreto n. 7.642, de 14 de dezembro de 2011. Institui o Programa Ciência sem Fronteiras. Diário Oficial da União. República Federativa do Brasil, 2011.

CARVALHO, Marília G. "É possivel transformar a minoria em equidade?". In: SIMPÓSIO GÊNERO E INDICADORES DA EDUCAÇÃO SUPERIOR BRASILEIRA, 2008, Brasília, MEC/INEP. Anais... Brasília: MEC/ INEP, 2008.

CATTAN, Nadine. "Students mobility, gender, and polycentrism in Europe". In: CATTAN, Nadine. Cities and networks in Europe: A critical approach of polycentrism. Acueil: John Libbey Eurotext, 2007. p. 139-148.

CHARLES, Christophe; VERGER, Jacques. História das universidades. São Paulo: EDUNESP, 1996.

COMMISSION EUROPÉENNE. Le programme ERASMUS: étudier en Europe et plus encore. Éducation et Formation, 2010.

DE WIT, Hans. "The internationalization of higher education in a global context". In: DE WIT, Hans. The dynamics of international student circulation in a global context. Leiden: Brill Sense, 2008. p. 1-14.

FELTRIN, Rebeca Buzzo; COSTA, Janaina Oliveira Pamplona da; VELHO, Léa. "Mulheres sem fronteiras? Uma análise da participação das mulheres no Programa Ciência sem Fronteiras da Unicamp: motivações, desafios e impactos na trajetória profissional". Cadernos Pagu [online], n. 48, 2016. el64804. Disponível em https://www.scielo.br/scielo.php?pid=S010483332016000300303\&script=sci abstract\&tIng=pt. Epub 01/12/2016. ISSN 1809-4449. https://doi. org/10.1590/18094449201600480004.

FREITAS, Lucas Bueno de; LUZ, Nanci Stancki da. "Gênero, Ciência e Tecnologia: estado da arte a partir de periódicos de gênero". Cadernos Pagu [online], n. 49, 2017. el 74908. Disponível em https://www.scielo. br/scielo.php?pid=S0104-83332017000100304\&script=sci abstract\&tlng=pt. Epub 13/03/2017. ISSN 1809-4449. https://doi.org/10.1590/18094449201700490008.

GUEDES, Moema de Castro; AZEVEDO, Nara; FERREIRA, Luiz Otávio. "A produtividade científica tem sexo? Um estudo sobre bolsistas de produtividade do CNPq". Cadernos Pagu, n. 45, p. 367-399, 2015.

HIRATA, Helena. Nova divisão sexual do trabalho? Um olhar voltado para a empresa e a sociedade. São Paulo: Boitempo, 2002. 
INEP. INSTITUTO NACIONAL DE ESTUDOS E PESQUISAS EDUCACIONAIS ANISIO TEIXEIRA. ResUmo Técnico - Censo da Educação Superior. Diretoria de Estatísticas Educacionais (DEED). Ministério da Educação, 2013.

JORDANOVA, Ludmilla. Nature Displayed. Gender, Science and Medicine 1760-1820. London; New York: Longman, 1999.

LASTRES, Helena Maria Martins; MELO, Hildete Pereira de; MARQUES, Teresa C. de Novaes. "Gênero no sistema de ciência, tecnologia e inovação no Brasil”. Gênero, v. 4, p. 73, 2004.

LETA, Jacqueline; LEWISON, Grant. "The contribution of women in Brazilian science: a case study in astronomy, immunology, and oceanography". Scientometrics, v. 57, n. 3, p. 339-53, 2003.

LIMA, Betina Stefanello; COSTA, Maria Conceição da. "Gênero, ciências e tecnologias: caminhos percorridos e novos desafios". Cadernos Pagu [online], Campinas, n. 48, 2016. e164805. Disponível em https://www.scielo.br/scielo.php?script=sci_abstract\&pid=S0104-83332016000300304\&lng=e n\&nrm=iso\&tlng=pt. Epub 01/12/2016. ISSN 1809-4449. https://doi.org/10.1590/18094449201600 480005 .

LOMBARDI, Maria Rosa. "Engenheiras Brasileiras: Inserção e Limites de Gênero no Campo Profissional". Cadernos de Pesquisa, v. 36, n. 127, jan./abr. 2006.

LOPES, Maria Margaret. "Sobre convenções em torno de argumentos de autoridade". Cadernos Pagu, n. 27, p. 35-61, 2006.

MAGALHÃES, Marcos N.; LIMA, Antônio Carlos P. Noções de probabilidade e estatística. 6. ed. São Paulo: EDUSP, 2004.

MAIA, Marcel Maggion. "Limites de gênero e presença feminina nos cursos superiores brasileiros do campo da computação". Cadernos Pagu, n. 46, p. 223-244, 2016.

MELO, Hildete Pereira de; RODRIGUES, Lígia Maria. Pioneiras das Ciências no Brasil. Rio de Janeiro: SBPC, 2006.

MELO, Hildete Pereira de. "Ciência e Tecnologia no Feminino 1990/1999". Revista Feminismos, v. 2, ก. 3, 2014.

MELO, Hildete Pereira de; RODRIGUES, Ligia. "Pioneiras da ciência no Brasil: uma história contada doze anos depois". Ciência e Cultura, v. 70, n. 3, p. 41-47, 2018.

MELO, Hildete Pereira de; LASTRES, Helena M. M. "Ciência e tecnologia numa perspectiva de gênero: o caso do CNPq". In: SANTOS, Lucy W. dos; ICHIKAWA, Elise Y.; CARGANO, Doralice de F. (Orgs.). Ciência, tecnologia e gênero: desvelando o feminino na construção do conhecimento. Londrina: Instituto Agronômico do Paraná, 2006. p. 129-160.

MELO, Hildete Pereira de; OLIVEIRA, André B. "A produção científica brasileira no feminino". Cadernos Pagu, Campinas, n. 27, p. 301-331, 2006.

MINELLA, Luzinete Simões. "Temáticas prioritárias no campo de gênero e ciências no Brasil: raça/ etnia, uma lacuna?". Cadernos Pagu, Campinas, n. 40, p. 95-140, 2013.

NOGUEIRA, Maria Alice. "Cosmopolitismo científico e escolarização dos filhos - o caso das famílias de ex-bolsistas no exterior". Relatório Final de Pesquisa. CNPq, 2007.

OCDE. ORGANIZAÇÃO PARA A COOPERAÇÃO E DESENVOLVIMENTO ECONÔMICO. "Qui sont les étudiants en mobilité international et où choissent-ils d'étudier?". Regards sur l'éducation 2009: les indicateus de l'OCDE. Paris: OCDE, 2010.

ROBERTSON, Susan. "Desafios enfrentados por universidades em um mundo em globalização". In: MOROSINI, Marilia C. (Org.). Qualidade na educação superior: reflexões e práticas investigativas. Porto Alegre: EDPUCRS, 2011 . p. 430-451, (Dados Eletrônicos).

ROSEMBERG, Fúlvia; ANDRADE Leandro F. "Ação Afirmativa no Ensino Superior Brasileiro: A Tensão entre Raça/Etnia e Gênero". Cadernos Pagu, Campinas, n. 31, p. 419-437, jul./dez. 2008.

SAITOVITCH, Elisa Maria Baggio; LIMA, Betina; BARBOSA, Márcia. "Gender equity in the brazilian physics community at present day". In: FIFTH IUPAP INTERNATIONAL CONFERENCE ON WOMEN IN PHYSICS AIP CONFERENCE PROCEEGINGS, Proceeedings..., 2015. 
SALVADOR, Sileide France Turan. Gênero na engenharia: o corpo docente em Curitiba/PR. 2011. Dissertação (Mestrado) - Universidade Tecnológica Federal do Paraná, Curitiba.

RAMOS, Milena Yumi. "Internacionalização da pós-graduação no Brasil: lógica e mecanismos". Educação e pesquisa [online], v. 44, 2018, e161579. Disponível em https://www.scielo.br/scielo. php?script=sci_arttext\&pid=S1517-97022018000100303\&lng=pt\&tIng=pt. Epub 22/06/2017. ISSN 1678-4634. https://doi.org/10.1590/s1517-9702201706161579.

Catarina Barbosa Torres Gomes (catarinagomes@cefetmg.br) é professora, doutora e mestre em Educação pela UFMG, com Graduação em Pedagogia e Filosofia pela UFOP Atualmente, é professora de Filosofia no Cefet/MG, na unidade de Araxá, atuando no ensino médio e técnico integrado, e no ensino superior, além de desenvolver pesquisas de Iniciação Científica, explorando a Internacionalização da Formação na perspectiva da Sociologia da Educação, Literatura (Clarice Lispector) e Filosofia (Simone de Beauvoir).

\section{COMO CITAR ESSE ARTIGO DE ACORDO COM AS NORMAS DA REVISTA}

GOMES, Catarina Barbosa Torres. "Desigualdade de Acesso ao Programa Ciência sem Fronteiras: uma interlocução com a perspectiva dos estudos de gênero". Revista Estudos Feministas, Florianópolis, v. 29, n. 1, e66177, 2021

\section{CONTRIBUIÇĀO DE AUTORIA}

Não se aplica.

\section{FINANCIAMENTO}

Não se aplica

\section{CONSENTIMENTO DE USO DE IMAGEM}

Não se aplica.

\section{APROVAÇĀO DE COMITÊ DE ÉTICA EM PESQUISA}

Parecer no 576.154, de 03/04/2014. CAAE: 27911114.0 .0000 .5149$.

\section{CONFLITO DE INTERESSES}

Não se aplica.

\section{LICENÇA DE USO}

Este artigo está licenciado sob a Licença Creative Commons CC-BY 4.0 International. Com essa licença você pode compartilhar, adaptar, criar para qualquer fim, desde que atribua a autoria da obra.

\section{HISTÓRICO}

Recebido em 10/07/2019

Reapresentado em 28/10/2020

Aprovado em 09/1 1/2020 